\title{
Outcome of Early Surgical Decompression in Traumatic Incomplete Spinal Cord Injury
}

\author{
Mohammed Ahmed Eissa1 ${ }^{1}$, Ahmed Elsharkawy ${ }^{1 *}$, Hieder Al-Shami², Aya Ouf ${ }^{3}$, \\ Ahmed M. Salah El-Din1 \\ ${ }^{1}$ Department of Neurosurgery, Cairo University, Cairo, Egypt \\ ${ }^{2}$ Department of Neurosurgery, Al-Ahly Bank Hospital, Cairo, Egypt \\ ${ }^{3}$ School of Medicine, Cairo University, Cairo, Egypt \\ Email: *shar.11.kawy@gmail.com
}

How to cite this paper: Eissa, M.A., Elsharkawy, A., Al-Shami, H., Ouf, A. and El-Din, A.M.S. (2020) Outcome of Early Surgical Decompression in Traumatic Incomplete Spinal Cord Injury. Open Journal of Modern Neurosurgery, 10, 353-363. https://doi.org/10.4236/ojmn.2020.103038

Received: May 15, 2020

Accepted: July 5, 2020

Published: July 8, 2020

Copyright () 2020 by author(s) and Scientific Research Publishing Inc. This work is licensed under the Creative Commons Attribution International License (CC BY 4.0).

http://creativecommons.org/licenses/by/4.0/ (c) (i) Open Access

\begin{abstract}
Objectives: Central cord syndrome has been reported to occur with particular frequency among older persons with cervical spondylosis who sustain hyperextension neck injury. This study aims to determine the efficacy of early surgical decompression (within 24 hours) of traumatic central cord syndrome patients in comparison with conservative management for central cord syndrome to determine a line of management to these cases. Methods: 60 patients suffering from acute traumatic central cord syndrome with various neurological deficits were divided into 2 groups, group A (conservatively managed) and group B (surgically managed). Patients in group B were operated upon within $24 \mathrm{hr}$. of trauma by posterior decompression. Clinical assessment of each patient on admission, discharge and 3 months follow-ups was done using the ASIA Impairment Scale, FIM, Ashworth scale, bladder function, and neuropathic pain symptoms. Results: Data collected from both groups showed, group A (the conservative group) consisted of 22 male (73.3\%) and 8 female subjects (26.6\%) with a mean age of 57.5 years while in group B (surgical group) the sample consisted of 20 male (66.6\%) and $10 \mathrm{fe}-$ male subjects (33.3\%) with a mean age of 58.6 years. There was an improvement in our study-according to ASIA and FIM scales-in 8 patients of 30 (26.6\%) in the conservative group. In the surgical group, improvement in 16 patients (53.3\%). Conclusions: Early surgical decompression with laminectomy and duroplasty can be considered a reliable modality in the management of traumatic CCS and can effectively reduce the secondary injury of the spinal cord and consequent deterioration with less hospital stay.
\end{abstract}

\section{Keywords}

Central Cord Syndrome "CCS", Early Surgical Decompression, Laminectomy, Duroplasty 


\section{Introduction}

Traumatic central cord syndrome (CCS) is the most common type of acute incomplete cervical spinal cord injury (SCI) which has been described many years ago by Schneider et al. in 1954 [1] [2]. It's often Happens in older people after experiencing a hyperextension injury that leads to a spinal cord contusion or edema [2]. It is characterized by disproportionately motoring deficit more on the arms, especially the hands, than the legs with bladder dysfunction and varying degrees of sensory loss below the lesion [3]. It occurs more frequently in patients with pre-existing anterior cervical spondylotic changes as bone spurs and in patients with thickened posterior ligamentum flavum [4].

In early description of acute traumatic CCS by Schneider in 1954, the management of traumatic CCS has been frequently discussed. In 1954 surgical management was not recommended, because the reasonably good prognosis of these cases and the spontaneous improvement and/or complete recovery may occur spontaneously [5] [6] [7]. More recent studies and expertise in this field, owing to changes in understanding of the pathophysiology indicate that conservative management and surgical decompression in some patients with persistent compression and neurological deficits can be both beneficial to the patients [7] [8] [9].

The idea of surgical decompressive in patients with ATCCS has been frequently discussed in the treatment of acute spinal cord injuries, if it is beneficial to the patients or even if it is safe [10] [11] [12] [13]. Surgical decompression by laminectomy might affect the stability of the spine with a possibility posttraumatic kyphotic deformity [14]. In some recent studies, early surgical decompression in the cases of traumatic SCI might be harmful and has no benefits to some patients and should be avoided [15] [16] [17].

In this study we aim to evaluate the functional outcome of early surgical decompression (within 24 hours) for ATCCS, where recovery of a certain degree of ambulation, activities of daily life, pain improvement and bladder function are evaluated.

\section{Patients and Methods}

This study was done prospectively in the Neurosurgery department, Cairo University hospitals, and conducted on 60 patients diagnosed with acute traumatic CCS. Data were collected over 18 months starting from January 2015 till June 2016. Cases had a follow up period of 6 months after discharge from hospital.

All cases were assessed clinically and radiologically by magnetic resonance imaging (MRI) and computed tomography (CT) and clinically on admission to the hospital.

\subsection{Inclusion and Exclusion Criteria}

\subsubsection{The Inclusion Criteria for the Patients Participating in Both Groups of This Study}

Ages from $40-78$, there was no preference for males or females, ATCCS patients 
with various degrees of neurological deficits, No history of associated medical disorders.

\subsubsection{The Exclusion Criteria}

The exclusion criteria were Non-traumatic cases, Hemodynamically unstable patients (spinal shock), Surgically unfit patients, Patients with disturbed conscious level and associated brain injuries.

Patients with cervical disc herniation or cervical fracture, other clinical incomplete spinal cord syndromes (Brown Sequard, anterior cord syndrome, posterior cord syndrome), complete spinal cord injury or presenting after 24 hours of trauma were excluded from this study.

Patients were divided into 2 groups according to their order at presentation, group A (the conservatively managed group was the odd order) and group B (surgically treated patients were the even order) with no bias to either group.

Initial management of all patients presenting with SCI begins in the field, with appropriate triage by emergency responders. Resuscitation according to the acute traumatic life support protocols should be followed by immobilization using backboard, rigid cervical collar or manual immobilization to prevent further cord damage [18].

Group A: conservative group $(\mathrm{n}=30)$ where patients received conservative medical treatment in the form of: immobilization of the neck with rigid cervical collar, Methylprednisolone administration starting $6 \mathrm{hr}$. after the injury and stopped after $48 \mathrm{hr}$. with dose of ( $100 \mathrm{mg}$ bolus followed by $25 \mathrm{mg}$ every $6 \mathrm{hr}$.) and rehabilitation with physical and occupational therapy.

Group B: surgical group $(\mathrm{n}=30)$. Patients were operated upon by cervical laminectomy and duroplasty within 24 hours of trauma. Duroplasty was done using the patient's own deep fascia of the thigh.

\subsection{Clinical Material}

The following data were collected for all subjects: gender, age at the time of injury, associated co-morbidities, hospital stay, treatment of the lesion (conservative or surgical), ASIA scale severity score (A, B, C, D, E) and FIM (functional independence measure) on admission (Table 1$)$.

\subsection{Follow-Up and Outcome}

- Group A:

All patients were admitted to the neurosurgical ward with close observation of motor power, spasticity and urinary and bowel continence monitoring until discharge. Initial CT scan and MRI were done within the first few hours of injury and then after 1 month and another one after 3 months from discharge. The average stay of the patients at the hospital was 25 days. After discharge each patient scheduled for follow up date each week for the first month and the less frequent for the rest of the follow-up period.

- Group B: 
Table 1. ASIA Impairment Scale (AIS) [19].

\begin{tabular}{|c|c|c|}
\hline Grade & Type of injury & Description of injury \\
\hline A & Complete & $\begin{array}{l}\text { No sensory or motor function is preserved in the sacral } \\
\text { segments S4 - S5. }\end{array}$ \\
\hline $\mathrm{B}$ & $\begin{array}{l}\text { Sensory } \\
\text { Incomplete }\end{array}$ & $\begin{array}{l}\text { Sensory but not motor function is preserved below the neurological } \\
\text { level and includes the sacral segments S4-S5, AND no motor } \\
\text { function is preserved more than three levels below the motor level } \\
\text { on either side of the body. }\end{array}$ \\
\hline $\mathrm{C}$ & $\begin{array}{c}\text { Motor } \\
\text { Incomplete }\end{array}$ & $\begin{array}{l}\text { Motor function is preserved below the neurological level AND } \\
\text { more than half of key muscle functions below the neurological } \\
\text { level of injury have a muscle grade less than } 3 \text { (Grades } 0 \text { - 2). }\end{array}$ \\
\hline $\mathrm{D}$ & $\begin{array}{c}\text { Motor } \\
\text { Incomplete }\end{array}$ & $\begin{array}{l}\text { Motor function is preserved below the neurological level AND } \\
\text { at least half (half or more) of key muscle functions below NLI } \\
\text { have a muscle grade } 3 \text { or more. }\end{array}$ \\
\hline $\mathrm{E}$ & Normal & $\begin{array}{l}\text { If sensation and motor function as tested with ISNCSCI are graded } \\
\text { as normal in all segments AND the patient had prior deficits } \\
\text { then the AIS Grade is E. }\end{array}$ \\
\hline \multicolumn{3}{|c|}{ Someone without a Spinal Cord Injury does not receive an AIS Grade. } \\
\hline
\end{tabular}

All patients were admitted to the neurosurgical ward with close observation of motor power, spasticity and urinary and bowel continence monitoring until discharge with medical care of the surgical wound or any post-surgical complications. Initial CT scan and MRI were done within the first few hours of injury and within the first $24 \mathrm{hr}$. after surgery. The average stay of the patients at the hospital was 14 days. After discharge each patient scheduled for follow up date each week for the first month and the less frequent for the rest of the follow-up period.

All patients in both groups were clinically assessed on admission, discharge and 3 months follow-up using the American Spinal Injury Association (ASIA) Impairment Scale, FIM (functional independence measure), spasticity (Ashworth) scale, bladder function, and neuropathic pain.

\section{Results}

Sixty cases with traumatic CCS were included in this study in the period from January 2015 to June 2016. In group A, there were 22 male patients (73.3\%) and 8 female patients (26.6\%). The age ranged from 40 to 73 years old with a mean of 57.5 years. In group B there were 20 male (66.6\%) and 10 female patients (33.3\%). The age ranged from 42 to 78 years old with a mean of 58.6 years.

\section{ASIA impairment scale and FIM assessments:}

In group A (Table 2, Table 3): On admission, 4 patients (13.3\%) patients were classified as ASIA A, 4 patients (13.3\%) as ASIA B, 10 patients (33.3\%) as ASIA C and 12 patients (40\%) as ASIA D. On discharge 4 patients (13.3\%) was classified as ASIA A, 4 patients (13.3\%) B, while 10 patients (33.3\%) scored ASIA C, 10 patients (33.3\%) ASIA D and 2 patients (6.6\%) was ASIA E. At follow-up there were 2 patients was ASIA A, 6 patients (20\%) as ASIA B, 6 patients $(20 \%)$ as ASIA C, 14 patients (46.6\%) as ASIA D and 2 patients (6.6\%) as ASIA E. 
Table 2. ASIA score of the conservative group.

\begin{tabular}{cccc}
\hline & Admission & Discharge & 3 months \\
\hline ASIA A & $4(13.3 \%)$ & $4(13.3 \%)$ & $2(6.6 \%)$ \\
ASIA B & $4(13.3 \%)$ & $4(13.3 \%)$ & $6(20 \%)$ \\
ASIA C & $10(33.3 \%)$ & $10(33.3 \%)$ & $6(20 \%)$ \\
ASIA D & $12(40 \%)$ & $10(33.3 \%)$ & $14(46.6 \%)$ \\
ASIA E & $0(0 \%)$ & $2(6.6 \%)$ & $2(6.6 \%)$ \\
\hline
\end{tabular}

Table 3. FIM of the conservative group.

\begin{tabular}{lccc}
\hline & Admission & Discharge & 3 months \\
\hline FIM 1 & $8(26.6 \%)$ & $8(26.6 \%)$ & $8(26.7 \%)$ \\
FIM 2 & $10(33.3 \%)$ & $10(33.3 \%)$ & $4(13.3 \%)$ \\
FIM 3 & $0(0 \%)$ & $0(0 \%)$ & $0(0 \%)$ \\
FIM 4 & $4(13.3 \%)$ & $4(13.3 \%)$ & $2(6.6 \%)$ \\
FIM 5 & $0(0 \%)$ & $0(0 \%)$ & $0(0 \%)$ \\
FIM 6 & $8(26.8 \%)$ & $6(20 \%)$ & $12(40 \%)$ \\
FIM 7 & $0(0 \%)$ & $2(6.6 \%)$ & $4(13.3 \%)$ \\
\hline
\end{tabular}

In group B (Table 4, Table 5): On admission preoperatively, 2 patients (6.6\%) patients were classified as ASIA A, 8 patients (26.6\%) as ASIA B, 14 patients (46.6\%) as ASIA C and 6 patients (20\%) as ASIA D. On discharge, 2 patients $(6.6 \%)$ ASIA A, 8 patients $(26.6 \%)$ B, while $10(33.3 \%)$ patients scored ASIA C, 8 patients (26.6\%) ASIA D and 2 patients (6.6\%) was ASIA E. At follow-up there were 6 patients (20\%) ASIA B, 8 patients (26.6\%) as ASIA C, 10 patients (33.3\%) ASIA D and 6 patients (20\%) ASIA E.

In the conservative group, two cases improved on discharge $(6.6 \%)$ and increased another 6 patients (20\%) at the 3 months follow up.

In the surgical group, 8 patients improved (26.6\%) and another 8 patients were added at the 3 months follow up.

Neuropathic pain: In group A it was presented in 6 patients (20\%) with complete recovery in 4 patients in the follow up period. In group B, pain was present in 8 patients (26.6\%) and was not recorded at the follow-up in any patient.

Spasticity: On admission it was present in 12 patients (40\%) in group A (Ashworth 3), in the follow up; spasticity was the same in 8 patients (26.6\%) but improved in 4 patients to (Ashworth 1). In group B, it was present in 14 patients (46.6\%) (Ashworth 3) and it was the same immediately after surgery and in the follow up after 2 weeks; the spasticity was reported only in 6 patients (20\%) (Ashworth 1) with minor improvements in the scheduled follow up appointments.

Urine retention: It was recorded in 10 patients in group A (33.3\%) with no improvement in 6 patients in the follow up examination. While in group B, it 
Table 4. ASIA score of the studied surgical group.

\begin{tabular}{cccc}
\hline & Admission & Discharge & 3 months \\
\hline ASIA A & $2(6.6 \%)$ & $2(6.6 \%)$ & $0(0 \%)$ \\
ASIA B & $8(26.6 \%)$ & $8(26.6 \%)$ & $6(20 \%)$ \\
ASIA C & $14(46.6 \%)$ & $10(33.3 \%)$ & $6(20 \%)$ \\
ASIA D & $6(20 \%)$ & $8(26.6 \%)$ & $10(33.3 \%)$ \\
ASIA E & $0(0 \%)$ & $2(6.6 \%)$ & $6(20 \%)$ \\
\hline
\end{tabular}

Table 5. FIM of the studied surgical group.

\begin{tabular}{lccc}
\hline & Admission & Discharge & 3 months \\
\hline FIM 1 & $10(33.3 \%)$ & $10(33.3 \%)$ & $8(26.6 \%)$ \\
FIM 2 & $14(46.6 \%)$ & $10(33.3 \%)$ & $6(20 \%)$ \\
FIM 3 & $0(0 \%)$ & $2(6.6 \%)$ & $0(0 \%)$ \\
FIM 4 & $2(6.6 \%)$ & $4(13.3 \%)$ & $2(6.6 \%)$ \\
FIM 5 & $0(0 \%)$ & $0(0 \%)$ & $0(0 \%)$ \\
FIM 6 & $4(13.3 \%)$ & $2(6.6 \%)$ & $10(33.3 \%)$ \\
FIM 7 & $0(0 \%)$ & $2(6.6 \%)$ & $4(13.3 \%)$ \\
\hline
\end{tabular}

was presented in 8 patients $(26.6 \%)$ on admission and in only 4 patients at the final follow up evaluation.

Post-operative complications: There were no post-operative complications in group $\mathrm{B}$.

\section{Discussion}

The conservative strategy of Schneider et al. was widely accepted until the early 1970s when Bosch et al. reported that many conservatively treated patients experienced a late onset neurological deterioration, and only $60 \%$ of them remained functional despite a period of initial improvement [20]. From a biological standpoint early decompression seemed to be the most effective management modality due to the prevention of secondary damage [21].

The patients' age in our study was ranging from 40 to 73 years in group A with mean age 57.5 years while ranging from 42 to 78 years with mean age 58.9 years in group B. The best outcome relative to FIM, Improvement of pain, spasticity and sphincteric control recorded in patients who were managed surgically with mean age 49.4 years and among patients whom were managed conservatively with mean age 52.5 years, may be related to higher incidence of comorbidities among elderly.

Roth et al. and Penrod et al. found that 29 of 30 (97\%) of the younger patients were ambulatory compared to 7 of 17 (41\%) of the older patients [22] [23]. Penrod also found that age was an adverse prognostic factor in relation to functional outcome [23]. Chen et al. also reported a rapid motor improvement 
achievement in a significant number of patients (82\%) under age 60 years in their 114 patients' series [24].

In Aito et al. study, a better neurological outcome was reported in younger patients compared to older ones. They reported independent ambulation in $87 \%$ - $97 \%$ in younger patients compared to $31 \%$ - $41 \%$ in the elderly (over 50 years of age at the time of injury) [25].

In 2009 Chen studied again that condition and he find that; the best outcomes were observed in patients of younger age when his study population mean age at the time of injury was 55.9 years old [26].

In our study we assessed all patients with ASIA and FIM and we compared the outcome in the two groups. In group A; the total improvement in our study was 8 patients $(26.6 \%)$ and in group B a total of 16 patients $(53.3 \%)$ clinically improved.

Since the 80's several studies have reported better clinical outcomes in early surgically treated patients with traumatic CCS when compared with medically treated patients. Despite these reports, early surgical treatment has not gained a wide popularity. Brodkey et al. demonstrated the development of delayed deterioration in seven patients with traumatic CCS. Surgical decompression was performed with a subsequent clinical improvement. The authors concluded that continued spinal cord compression resulted in neurological deterioration, and they advised early surgical decompression so to prevent this scenario [27].

Similarly, Bose et al. in 1984 also reported significantly improved motor scores and function in surgically treated patients compared with conservatively managed patients in their 28 series study [28].

More recently, Lenehan et al. prospectively reviewed 73 patients with spondylotic CCS. The authors reported significant improvement in ASIA scores at 6 and 12 months in early ( $<24$ hours) surgically treated patients in comparison with patients treated with either delayed decompression ( $>24$ hours) or medically treated [29].

\section{Study Limitations:}

The lack of intra-operative neurophysiological monitoring and navigation due to high cost and low resources.

The follow up period is short due to shortage of resources and the poor database and archival in the hospital and the failure to contact some patients after discharge. Many patients are lost to follow up, especially those who have to travel to this tertiary care facility. An extended period of follow up more than 48 months to 5 years at least is required for analysis of rehabilitation and return to work to be included in the final judgment during comparison of these surgical techniques.

An accurate hospital stay cost per patient could not be calculated as the Cairo University hospital is a teaching hospital affiliated to Cairo University and operates on governmental funds and provides care free of charge to its patients. $\mathrm{Pa}$ tients are not billed for neither ER nor operative costs. 


\section{Conclusions}

While early surgical intervention does not significantly surpass conservative management overall, it offers a safe and fast path to neurological improvement in the ASIA grades in patients with ATCCS. Another important aspect is that surgical intervention minimizes hospital stay and thus, offers a financially convenient solution in third world countries for both the patient and the medical facility during the whole period of management of these cases. Surgical Decompression can be considered a reliable modality in the management of traumatic CCS, effectively reducing the secondary injury of the spinal cord and consequent deterioration with less hospital stay in comparison to the conservative management of these cases; putting in consideration the low socioeconomic state of patients treated in our facility and the poor finances of our hospital.

Cervical laminectomy is a safe, low morbidity, decompressive procedure and in this study, we did not face any post-operative increased incidence of neurological deterioration or instability in the short term of the follow-up period.

\section{Acknowledgements}

Not applicable.

\section{Funding}

No fund was needed.

\section{Availability of Data and Materials}

All datasets generated and analyzed in during the current study are not publicly available, but are available by reasonable request from the corresponding author.

\section{Authors' Contribution}

$\mathrm{AE}$ and HA carried out the literature search and review. AE and HA carried out the manuscript preparation. AM performed the manuscript editing. ME collected the clinical and surgical data. All authors read and approved the final manuscript.

\section{Ethics Approval and Consent to Participate}

Based upon regulations of Cairo University Hospitals ethical committee, ethics approval and consent from patients was obtained.

\section{Consent for Publication}

Written informed consent was obtained from the patient for publication of this case report and accompanying images.

\section{Conflicts of Interest}

The authors declare that they have no competing interests. 


\section{References}

[1] Stevenson, C.M., Dargan, D.P., Warnock, J., et al. (2016) Traumatic Central Cord Syndrome: Neurological and Functional Outcome at 3 Years. Spinal Cord, 54, 1010-1015. https://doi.org/10.1038/sc.2016.34

[2] Patel, R., Joel, A., Chavda, Y. and Powell, S. (2017) A Case of Traumatic Central Cord Syndrome. Visual Journal of Emergency Medicine, 8, 74-75.

https://doi.org/10.1016/j.visj.2017.04.016

[3] Haritonov, D., Kalevski, S., Peev, N. and Kalevska, E. (2015) Timing of Operative Management in Patient with Traumatic Central Cord Syndrome. Scripta Scientifica Medica. https://doi.org/10.14748/ssm.v46i4.627

[4] Liu, Y., Wang, Z., Yang, S., Yang, H. and Zou, J. (2017) The Effect of Surgical Intervention for Delayed Cervical Central Cord Syndrome. BioMed Research International, 2017, Article ID: 7979850. https://doi.org/10.1155/2017/7979850

[5] Aarabi, B., Hadley, M.N., Dhall, S.S., et al. (2013) Management of Acute Traumatic Central Cord Syndrome (ATCCS). Literature Review in Neurosurgery, 72, 195-204. https://doi.org/10.1227/NEU.0b013e318276f64b

[6] Jin, W., Sun, X., Shen, K., et al. (2017) Recurrent Neurological Deterioration after Conservative Treatment for Acute Traumatic Central Cord Syndrome without Bony Injury: Seventeen Operative Case Reports. Journal of Neurotrauma, 34, 3051-3057. https://doi.org/10.1089/neu.2016.4706

[7] Uribe, J., Green, B.A., Vanni, S., Moza, K., Guest, J.D. and Levi, A.D. (2005) Acute Traumatic Central Cord Syndrome-Experience Using Surgical Decompression with Open-Door Expansile Cervical Laminoplasty. Surgical Neurology, 63, 505-510. https://doi.org/10.1016/j.surneu.2004.09.037

[8] Schadler, P., Shue, J. and Girardi, F. (2016) Central Cord Syndrome: A Review of Epidemiology, Treatment and Prognostic Factors. JSM Neurosurgery and Spine, 4, 1075.

[9] Ramírez, N.B., Arias-Berríos, R.E., López-Acevedo, C. and Ramos, E. (2016) Traumatic Central Cord Syndrome after Blunt Cervical Trauma: A Pediatric Case Report. Spinal Cord Series and Cases, 2, 16014. https://doi.org/10.1038/scsandc.2016.14

[10] Bedbrook, G.M. (1979) Spinal Injuries with Tetraplegia and Paraplegia. The Journal of Bone and Joint Surgery, 61, 267-284. https://doi.org/10.1302/0301-620X.61B3.225332

[11] Dall, D.M. (1972) Injuries of the Cervical Spine. II. Does Anatomical Reduction of the Bony Injuries Improve the Prognosis for Spinal Cord Recovery? South African Medical Journal, 46, 1083-1090.

[12] Dall, D.M. (1972) Injuries of the Cervical Spine. I. Does the Type of Bony Injury Affect Spinal Cord Recovery? South African Medical Journal, 46, 1048-1056.

[13] Dolan, E.J., Tator, C.H. and Endrenyi, L. (1980) The Value of Decompression for Acute Experimental Spinal Cord Compression Injury. Journal of Neurosurgery, 30, 693-697. https://doi.org/10.3171/jns.1980.53.6.0749

[14] Malcom, B.W., Bradford, D.S., Winter, R.B. and Chou, S.N. (1981) Post-Traumatic Kyphosis: A Review of 48 Surgically Treated Patient. Journal of Bone and Joint Surgery, 63, 891-899. https://doi.org/10.2106/00004623-198163060-00005

[15] Heiden, J.S., Weiss, M.H., Rosenberg, A.W., Apuzzo, M.L. and Kurze, T. (1975) Management of Cervical Spinal Cord Trauma in Southern California. Journal of Neurosurgery, 3, 732-736. https://doi.org/10.3171/jns.1975.43.6.0732 
[16] Maroon, J.C., Abla, A.A., Wilberger, J.I., Bailes, J.E. and Sternau, L. (1991) Central Cord Syndrome. Clinical Neurosurgery, 37, 612-621.

[17] Vaccaro, A.R., Daugherty, R.J., Sheehan, T.P., et al. (1997) Neurologic Outcome of Early versus Late Surgery for Cervical Spinal Cord Injury. Spine, 22, 2609-2613. https://doi.org/10.1097/00007632-199711150-00006

[18] Resnick, D.K. (2013) Updated Guidelines for the Management of Acute Cervical Spine and Spinal Cord Injury. Neurosurgery, 72, 1. https://doi.org/10.1227/NEU.0b013e318276ee7e

[19] Burns, S., Biering-Sørensen, F., Donovan, W., et al. (2012) International Standards for Neurological Classification of Spinal Cord Injury, Revised 2011. The Journal of Spinal Cord Medicine, 34, 535-546. https://doi.org/10.1310/sci1801-85

[20] Bosch, A., Stauffer, E.S. and Nickel, V.L. (1971) Incomplete Traumatic Quadriplegia: A Ten-Year Review. JAMA: The Journal of the American Medical Association, 216, 473-478. https://doi.org/10.1001/jama.1971.03180290049006

[21] Guest, J., Eleraky, M.A., Apostolides, P.J., Dickman, C.A. and Sonntag, V.K.H. (2002) Traumatic Central Cord Syndrome: Results of Surgical Management. Journal of Neurosurgery, 97, 25-32. https://doi.org/10.3171/spi.2002.97.1.0025

[22] Roth, E.J., Lawler, M.H. and Yarkony, G.M. (1990) Traumatic Central Cord Syndrome: Clinical Features and Functional Outcomes. Archives of Physical Medicine and Rehabilitation, 71, 18-23.

[23] Penrod, L.E., Hegde, S.K. and Ditunno, J.F. (1990) Age Effect on Prognosis for Functional Recovery in Acute, Traumatic Central Cord Syndrome. Archives of Physical Medicine and Rehabilitation, 71, 963-968.

[24] Chen, T.Y., Lee, S.T., Lui, T.N., et al. (1997) Efficacy of Surgical Treatment in Traumatic Central Cord Syndrome. Surgical Neurology, 48, 435-440. https://doi.org/10.1016/S0090-3019(97)00037-2

[25] Aito, S., D’Andrea, M., Werhagen, L., et al. (2007) Neurological and Functional Outcome in Traumatic Central Cord Syndrome. Spinal Cord, 45, 292-297. https://doi.org/10.1038/sj.sc.3101944

[26] Chen, L., Yang, H., Yang, T., Xu, Y., Bao, Z. and Tang, T. (2009) Effectiveness of Surgical Treatment for Traumatic Central Cord Syndrome: Clinical Article. Journal of Neurosurgery: Spine, 10, 3-8. https://doi.org/10.3171/2008.9.SPI0822

[27] Brodkey, J.S., Miller, C.F. and Harmody, R.M. (1980) The Syndrome of Acute Central Cervical Spinal Cord Injury Revisited. Surgical Neurology, 14, 251-257.

[28] Bose, B., Northrup, B.E., Osterholm, J.L., Cotler, J.M. and DiTunno, J.F. (1984) Reanalysis of Central Cervical Cord Injury Management. Neurosurgery, 15, 367-372. https://doi.org/10.1227/00006123-198409000-00012

[29] Lenehan, B., Fisher, C.G., Vaccaro, A., Fehlings, M., Aarabi, B. and Dvorak, M.F. (2010) The Urgency of Surgical Decompression in Acute Central Cord Injuries with Spondylosis and without Instability. Spine (Phila Pa 1976), 35, S180-S186. https://doi.org/10.1097/BRS.0b013e3181f32a44 


\section{Abbreviations Used in This Paper}

CCS $=$ Central Cord Syndrome; ATCCS = Acute Traumatic Central Cord Syndrome; ASIA $=$ American Spinal Injury Association; FIM $=$ Functional Independence Measure; SCI = Spinal Cord Injury; MRI = Magnetic Resonance Imaging; $\mathrm{CT}=$ Computed Tomography. 